\title{
Franco y las potencias del Eje. La tentación intervencionista de España en la segunda guerra mundial
}

\author{
ANGELES EGIDO LEÓN
}

Aunque ya no es posible dudar de la no neutralidad de Franco en la segunda guerra mundial, no resulta ocioso examinar su curiosa y no menos oportunista evolución desde la neutralidad a la no beligerancia (pro-Eje) para acabar en una neutralidad que favorecía a los aliados. En este artículo se analizan los momentos en que la tentación intervencionista fue más fuerte y los motivos por los que, a pesar de la intención, tal tentación no cuajó.

\section{DE LA NEUTRALIDAD A LA NO BELIGERANCIA: FRANCO SE OFRECE A ENTRAR EN LA GUERRA}

Cuando el 1 de septiembre de 1939 el ataque alemán a Polonia desencadenó el comienzo de la segunda guerra mundial, Franco tardó apenas tres días en declararse neutral. El rápido avance alemán sobre los países nórdicos, la caída de Francia y la entrada de Italia en la guerra harian, sin embargo, cambiar muy pronto esta decisión. En efecto, cuando Mussolini entró en la guerra al lado de Alemania, el 10 de junio de 1940, Franco le envió una carta en la que le comunicaba, además de su solidaridad, el paso de España de la neutralidad a la no beligerancia, 
fórmula jurídica acuñada por el Duce y que tras el precedente italiano se consideraba de hecho como un paso previo a la beligerancia ${ }^{1}$.

El cambio de postura de Mussolini debió producirse a mediados de marzo de 1940, cuando Hitler le comunicó la inminencia del ataque a Francia y Bélgica. Más tarde confesaría a Ciano que le resultaba humillante permanecer cruzado de brazos mientras otros escribian la historia. Pero sobre todo no quería quedar ajeno al reparto tras la victoria. En cuanto a la decisión de Franco, puede interpretarse como el deseo de aprovechar conyunturalmente la situación, especialmente el colapso fracés, para intentar lograr por sí mismo, amparado en la amistad con sus aliados ideológicos, los objetivos del régimen en política exterior; aunque tampoco puede descartarse, máxime tras el precedente italiano, que fuera el primer paso para una incorporación gradual de España al conflicto, especialmente cuando la "guerra relámpago» parecía llamada a acabar rápidamente con la resistencia británica ${ }^{2}$.

Hacia el primer argumento apunta la ocupación de Tánger por tropas españolas el 14 de junio, cuando los alemanes estaban a las puertas de París. Y el hecho de que, cuando el nuevo Gabinete francés presidido por Pétain solicitó el armisticio, Franco no dudara en aprovechar la ocasión para presentar las reivindicaciones territoriales españolas. El 16 de junio el general Vigón se entrevistaba con Hitler portando una carta de Franco en este sentido. El 19, la Embajada española en Berlín presentaba un memorándum en el que eran detalladamente expuestas: cesión del Marruecos francés y Orán y ampliación de los territorios saharianos y del golfo de Guinea. A cambio, España entraría en la guerra, tras un período de preparación de la opinión pública y previo envío de Alemania del material indispensable. Mussolini, por su parte, había insinuado a Franco que en la nueva sistematización del área mediterránea resultante de la guerra, Gibraltar pasaría a manos de España. Quedaba, pues, cerrado al círculo tradicional de las reivindicaciones franquistas en política exterior.

1 Una definición de la no beligerancia acorde con la interpretación que se le dio en España puede verse en E. BORCHARD, “War, Neutrality and Non-belligerancy" en American Journal of Internacional Law, enero 1941, pág. 624. Un estudio sobre la evolución española en V. MoRAles LezCANO, $H^{a}$ de la no beligerancia española durante la segunda guerra mundial, Ediciones de la Mancomunidad de Cabildos, Valencia-Las Palmas 1980.

${ }^{2}$ Vid. V. Morales-LezCANo, "Las causas de la no beligerancia española, reconsideradas" en Revista de Estudios Internacionales, N. ${ }^{\circ} 3$, julio-septiembre 1984, págs. 609-631. 
Hacia el segundo, la reciente revisión del Fondo Lancellotti, que revela la existencia de un grado de compromiso mayor por parte de España de lo que hasta ahora se había venido admitiendo. Concretamente, la disposición de permitir que aeroplanos italianos repostasen en aeropuertos españoles a la vuelta de una importante acción de guerra: el bombardeo de ese Gibraltar que Mussolini había prometido a Franco ${ }^{3}$. En el contexto inmediato a la entrada de Italia en la guerra esta hipótesis cobra sentido, dado que los italianos pensaban en atacar a los británicos, manteniendo una postura más pasiva respecto a Francia.

Por su parte, Gran Bretaña, desde la caída de Francia, había orientado claramente su política a mantener a España alejada de la guerra. Su intervención proporcionaría al Eje el control del Estrecho, dificultando seriamente las líneas de comunicación en el Atlántico. Para evitarlo, los británicos, en conjunción con el Estado Mayor francés, habían venido considerando una serie de planes para asegurar el archipiélago balear y las islas españolas y portuguesas en el Atlántico. Paralelamente se había diseñado una operación diplomática de largo alcance. España y Portugal estaban ligadas por el llamado Pacto Ibérico que era en realidad un tratado de amistad y no agresión firmado en Lisboa el 17 de marzo de 1939. Pero, ante la declaración de no beligerancia española, Portugal consideró necesario reforzarlo con un protocolo adicional que garantizase que la neutralidad portuguesa no sería violada. Los portugueses temían que una vinculación directa o indirecta de España con el Eje se tradujera o bien en que España permitiera el paso de tropas alemanas en dirección a Portugal, o bien que ella misma se encargase de la operación.

Cabía especular, dada la sempiterna alianza portuguesa con Gran Bretaña, sobre la injerencia británica en este nuevo acuerdo. Pero parece que en este caso, aunque una convergencia neutralista peninsular favorecía indudablemente los intereses británicos, la iniciativa partió exclusivamente de Portugal y respondió prioritariamente a su necesidad de salvaguardar su territorio ante la eventualidad de una posible invasión ${ }^{4}$. Así lo confirma, de hecho, el texto del protocolo, firmado el 29 de julio de 1940. El acuerdo, no obstante, aunque tranquilizó por el momento a ambas partes, era lo bastante ambiguo como para no comprometerlas de12-14.

${ }^{3}$ Vid. J. TuSELL, "Franco no fue neutral» en Historia $16, \mathrm{~N}^{\circ}{ }^{\circ} 141$, enero 1988 , págs.

${ }^{4}$ Vid. I. Delgado, Portugal e a guerra civil de Espanha, Publicaçoes Europa-América, Lisboa 1981, págs. 197-202. 
masiado. En realidad, España no logró lo que presumiblemente buscaba: atraer a Portugal apartándolo de su secular alianza británica y vincularla de algún modo, a través de la amistad española, a las potencias del Eje. Tampoco Portugal obtuvo una garantía total, tal como hubiera deseado Londres, de que el statu quo peninsular (léase Gibraltar) no sería alterado. No obstante, de cara a la opinión internacional, el equivoco no se deshizo, ateniéndose cada bando a la interpretación que más le convenía ${ }^{5}$.

\section{CONTACTOS CON ALEMANIA: SERRANO SÚÑER VIAJA A BERLIN}

Tal era la situación que enmarcó el ofrecimiento de Franco a Hitler para entrar en la guerra, en un momento en que el interés alemán por Gibraltar era evidente máxime cuando tras el armisticio con Francia se hizo patente el propósito británico de resistir ${ }^{6}$. El verano de 1940 fue, en efecto, el período en el que los contactos germano-españoles fueron más intensos y durante el cual Hitler consideró más seriamente la conveniencia de que España entrara en la guerra. En julio había viajado a España el almirante Canaris para preparar un plan militar destinado a tomar Gibraltar con apoyo italiano y español. Era una alternativa a la operación "Seeloewe" de invasión del Reino Unido. A principios de septiembre lo haría el general Von Richtofen, que garantizó el envío de suministros y materias primas imprescindibles para que España pudiera hacer frente a la situación. Pocos días después salía Serrano Súñer para Berlín.

Como queda dicho, las aspiraciones españolas se centraban en las reivindicaciones tradicionales en el norte de África, especialmente en Marruecos a costa de las posesiones francesas, sin descartar naturalmente la ocupación de Gibraltar ${ }^{7}$. Pero aunque a Hitler le preocupaba una po-

${ }^{5}$ Como ha subrayado E. SACRISTAN LUCAS: "Relaciones peninsulares durante la segunda guerra mundial", en Proserpina, N. ${ }^{0} 1$, dic. 1984, pág. 150.

${ }_{6}^{6}$ Vid. A. Marquina Barrio, España en la política de seguridad occidental, 1939-1986, Ediciones Ejércíto, Madrid 1986, pág. 26 y ss.; y Documents on German Foreign Policy, serie D, Vols. VI-XIII, Londres, Stationary Óffice 1956-64.

${ }^{7}$ El tono que alcanzaron quedó reflejado en la conocida obra de J. M. ARElLzA y F. M. Castiella: Reivindicaciones de España, IEP. Madrid 1941; en folletos como el de J. M. Cordero Torres: Aspectos de la misión universal de España, Ed. Vicesecretaría de Educación Popular, Madrid 1944; y en el libro, más objetivo, de C. Barcia Trelles: Puntos cardinales de la política internacional de España, Ediciones FE. Madrid 1939. 
sible maniobra británica para colocar contra Pétain a las colonias francesas norteafricanas, más tade confesaría a Ciano que no le interesaba que el Marruecos francés pasara a manos de España provocando una presumible reacción gala. Por otra parte, la operación conjunta sobre Gibraltar, destinada a evitar la interferencia británica en el Mediterráneo, objetivo fundamental que cubriría España con su entrada, era un elemento más para convencer a Gran Bretaña de su situación de resistencia sin esperanza, pero no el único ni por supuesto el decisivo.

Los alemanes solicitaron también, a través de Ribbentrop, que así se lo expuso a Serrano en la primera entrevista que celebraron, una de las islas Canarias y bases en Agadir y Modagor. A cambio, Hitler sólo prometía con claridad la ayuda militar y económica, pero el tema de Marruecos quedaba desdibujado en una hipotética división del norte de África entre España, Alemania e Italia, cuyos oficios como mediadora fueron repetidamente utilizados por ambas partes. Si el Duce estaba de acuerdo, Alemania firmaría un tratado con España que permitiría ocupar rápidamente Gibraltar. No se mencionaron las aspiraciones alemanas sobre Canarias y la costa atlántica marroqui ${ }^{8}$. La posición de Mussolini entonces fue ambigua. Aseguró que la carta española debía jugarse a su debido tiempo y dejó caer la idea de que en lugar de un protocolo hispano-germano podía llegarse a una alianza militar entre España, Alemania e italia ${ }^{9}$.

No se llegó a un acuerdo. En realidad, se puso de manifiesto to mucho que separaba a España y Alemania. No se trataba ya de que entrase o no en la guerra, sino de que pedía compesaciones por hacerlo y veía en las exigencias alemanas, sobre todo respecto a Canarias, una presión inaceptable. Por su parte Hitler, como confesó a Mussolini en el Brennero, juzgaba excesivas las pretensiones españolas. El Duce no sólo estuvo de acuerdo, sino que afirmó por su parte que consideraba la no beligerancia española más ventajosa que la intervención. Serrano volvió a España sin percatarse de la firme posición alemana e italiana, saldándose su visita con un fracaso, puesto que no había conseguido su objetivo: negociar la entrada de España en la guerra a cambio de

8 J. Tusell y G. Garcia Queipo de Llano, Franco y Mussolini. La política española durante la segunda guerra mundial. Planea, Barcelona 1985, pág. 105.

${ }^{9}$ Ibidem, págs. 106-108; y A. MARQuINA, ob. cit., pág. 34. 
concesiones territoriales, por mucho que intentara justificarse de lo contrario ${ }^{10}$.

\section{LA ENTREVISTA DE HENDAYA}

Tal era el ambiente que precedió a la entrevista de Hendaya, que tuvo lugar el 23 de octubre de 1940. El Führer se había reunido el día anterior con Pierre Laval y había dejado concertada una entrevista para el siguiente con Pétain. Esto da idea de hasta qué punto tenía en consideración la postura francesa ante las conocidas pretensiones españolas en Marruecos. Franco, por su parte, había pedido opinión a seis generales y todos coincidieron en que debía mantenerlas. No hay que olvidar que la tensión entre los militares y Serrano, que acababa de desplazar a Beigbeder -cuyo comportamiento un tanto ambiguo le había hecho sospechoso de anglofilia ${ }^{11}$ - de la cartera de Exteriores, era creciente y sus ideas intervencionistas distaban de ser compartidas unánimemente. Lejos de ello, los generales más antiguos habían formado una Junta Militar con apoyo del Reino Unido para impedir que Falange las llevara hasta sus últimas consecuencias.

Del desarrollo de la entrevista, que sólo nos es conocida parcialmente -la minuta española se perdió y la alemana se conserva considerablemente recortada -, parece deducirse que Franco estuvo mal informado de los planteamientos alemanes. Presentó a Hitler la difícil situación por la que atravesaban los españoles y la necesidad de justificar la intervención con compesaciones territoriales. Se enzarzó en disgresiones económicas y estratégicas, y no debió causar una impresión muy positiva. Hitler estaba convencido de que la guerra se decidiría a su favor. Le preocupaba una posible ocupación aliada de las islas atlánticas que podía alimentar la subversión de las colonias francesas contra Pétain, pero no estaba dispuesto a sacrificar a Francia. Si España formaba parte del frente contra Gran Bretaña y Francia, la guerra podía acabar rápidamente. Podía obtener algunas concesiones en el norte de África, siempre que

10 Vid. R. Serrano Súner, Entre Hendaya y Gibraltar. Frente a una leyenda, Ediciones y Publicaciones Españolas, Madrid 1947, págs. 199-204.

${ }^{11}$ Vid. M. Espadas Burgos, Franquismo y política exterior, Rialp, Madrid 1987, pág. 110 y $\mathrm{CH}$. R. HALSTEAD, «Un 'Africain' meconnu: le Colonel Juan Beigbeder», en Revue d'Histoire de la Deuxième Guerre Mondiale, XXI-3, junio 1987, págs. 31-60. 
se tuvieran en cuenta los intereses franceses, alemanes e italianos, pero la única contrapartida clara fue Gibraltar. A pesar de la vaguedad de la oferta, España firmó el texto de protocolo preparado por los alemanes, adhiriéndose al Pacto de Acero y declarándose dispuesta a entrar en el pacto tripartito y a declarar la guerra al Reino Unido en una fecha a determinar. España, como ha subrayado Marquina ${ }^{12}$, perdía su neutralidad a cambio de un futurible, pero no había compromiso militar efectivo, y de hecho Hitler quedó convencido de que no obtendría ayuda militar de España en la guerra. En este sentido pudo considerarse Hendaya punto final. Sin embargo, no lo fue del todo ${ }^{13}$.

En efecto, un acontecimiento inesperado permitiría a España reabrir la cuestión. El 28 de octubre, es decir, cinco días después de la entrevista de Hendaya, Mussolini inició un ataque a Grecia que sería un auténtico desastre. Franco envió una carta a Hitler recordándole las aspiraciones españolas y Serrano fue llamado a Berchtesgaden. El motivo no podía ser otro que solicitar la entrada de España en la guerra. Hitler le explicó la difícil situación creada por el ataque a Grecia y las nuevas directrices sobre Gibraltar que se plasmaron en el plan Félix, que preveía el cierre del Estrecho y el paso de tropas alemanas al Marruecos espanol. Hitler seguía sin querer sacrificar a Francia, pero continuaba considerando el ataque a Gibraltar como un golpe decisivo en sus efectos psicológicos sobre el Reino Unido. Se fijó el tiempo para la operación que ya se tenía decidida y que conduciría a un éxito rápido. Franco hubo de enfrentarse, en consecuencia, a la propuesta de entrar en la guerra el 10 de enero del 41. Pero la respuesta española se hizo esperar y Hitler, irritado, solicitó la mediación italiana. El 12 de febrero Franco y Mussolini se entrevistaban en Bordighera.

Aunque el Duce reconoció que la conversación habia sido sugerida por Hitler en el Berghof, no apremió a Franco tanto como aquél hubiera deseado. En realidad, la postura del Duce queda aquí al descubierto: mientras había considerado a España un satélite más o menos manejable al que aconsejaba paternalmente, todo había marchado sobre ruedas;

12 A. Marquina, ob. cit, pág. 40.

13 Cfr. R. DE LA Cienva: Hendaya, punto final, Planeta, Barcelona 1981; D. Detwiles, Hitler, Franco und Gibraltar. Die Frage des Spanischen Eintritts in den Zweiten Weltkrieg. Verlag, Wiesbaden 1962; у R. Pностов, Agonía de in neutral. Las relaciones hispanoalemanas durante la segunda guerra mundial y la División Azul, Editora Nacional, Madrid 1972. También las "Memorias" de R. SerRano Súñer, Entre el silencio y la propaganda. La historia como fue, Planeta, Barcelona 1977. 
pero cuando Franco tomó la iniciativa reclamando las aspiraciones españolas en África, se acrecentó la reserva italiana ante un posible competidor en el Mediterráneo ${ }^{14}$. En Bordighera paradójicamente quedó claro que España ya no intervendría en la guerra, cerrándose así el período en el que la tentación intervencionista española fue más fuerte: entre junio del 40 y febrero del 41 , coincidiendo con el momento de mayor ascendiente de Serrano y las presiones conjuntas del Eje, aunque mucho menos fuertes por parte italiana de lo que Hitler hubiera deseado.

\section{LOS NUEVOS PLANES ALEMANES; LA CAMPAÑA DE RUSIA}

En cualquier caso, a fines de marzo del 41 la evolución de la guerra favorecía nuevamente al Eje. Hitler había conseguido invertir la difícil situación creada por los italianos en Grecia y su objetivo prioritario sería a partir de entonces Rusia. En efecto, el 21 de junio del 41 Alemania atacaba a la URSS. Se abria de este modo el frente del Este. Para entonces, la situación en España también había variado. Serrano, que con su afán de protagonismo se había creado no pocos enemigos, empezó a caer en desgracia. La gota que colmó el vaso fue un discurso que el propio Serrano pronunció en Mota del Cuervo haciendo declaraciones claramente contrarias a los aliados y reclamando el monopolio del poder para la Falange.

En medio de este clima, Franco desencadenó la crisis del Gobierno. En el nuevo que se formó había tres ministros falangistas, desplazando asi el protagonismo de Serrano, y un tradicionalista. Galarza ocupaba la cartera de Gobernación y dos militares antiserranistas y antifalangistas, Orgaz y Kindelán, accedian a importantes puestos militares. Aplicando la táctica de divide y vencerás, Franco consolidaba su propio papel de árbitro, afianzando su poder personal y frenando, de cara al exterior, los

\footnotetext{
${ }^{14}$ La consulta de la biografía de R. DE FELICE, en realidad una historia de la era fascista, es de gran utilidad para el seguimiento de las relaciones hispano-italianas; en especial el volumen Mussolini il Duce. Lo stato totalitario 1936-1940, Einaudi, Turín 1981. También hay documentación publicada: Documenti diplomatici italiani, VIII serie 1935-39 y IX serie 1939-43, Librería dello Stato, 1952-1965; Opera omnia di Benito Mussolini, a cura di Edoardo e Duilio Susmel, Florencia, La Fenice 1960 y Giovanni Volpe 1978; y L'Europe verso la catastrofe. Colloqui con Mussolini, Hitler, Franco etc., verbalitzzati de Galeazzo Ciano, Mondadori 1948.
} 
fervores intervencionistas encarnados en la figura de Serrano. Fervores, por otra parte, ya bastante atenuados desde que Hitler se negó a aceptar las reivindicaciones españolas y desde que el eje de la guerra se alejó del Mediterráneo, zona especialmente sensible para los intereses españoles. Por otra parte, la apertura de un nuevo frente, cuando el anterior seguía sin dirimirse, auguraba la evidencia de una guerra larga y esta era una perspectiva que un país como España, recién salido de una guerra civil y con graves dificultades económicas, no podía obviamente afrontar.

La reacción española ante la campaña de Rusia es sobradamente conocida ${ }^{15}$. Serrano, en un intento de dulcificar las relaciones con Alemania, un tanto enfriadas por la negativa española a participar en la operación conjunta sobre Gibraltar, monopolizó para Falange la idea y el reclutamiento de la «División Azul». Todos vieron en ello una maniobra personal. Fue entonces cuando Franco realizó, en un discurso con motivo del $5 .^{\circ}$ aniversario del alzamiento, unas intempestivas declaraciones a favor del Eje. Eran las primeras que hacía en este sentido desde el comienzo de la guerra. Desde luego tuvo que ser consciente de que el gesto redundaría, cuando menos, en un aumento de la presión económica aliada sobre España, por lo que se han interpretado como una maniobra política. En un momento en que, ante el debilitamiento de la posición británica en el Mediterráneo y el estallido de la guerra germanosoviética, se acentuaban las presiones intervencionistas contra el comunismo y contra la tutela británica, como continuación de la línea mantenida durante la guerra civil, la declaración verbal alejaría, desde el punto de vista de Franco, el peligro de la participación real ${ }^{16}$.

El discurso, en cualquier caso, alertó a los aliados que volvieron a pensar en atacar Canarias antes de que los alemanes consolidasen el frente ruso. De hecho, la toma de estas islas, junto con las Azores, como bases alternativas a Gibraltar, se había barajado en numerosos proyectos por la coalición anglo-norteamericana durante los años 40-41. El Gobierno español tenía indicios de que se planeaba alguna operación de este tipo y a finales del 41 la preocupación se incrementó por la incertidumbre

${ }^{15}$ Vid. G. R. KLIENFELd y L. A. TamBs, Hitler's Spanish Legion. The Blue Division in Rusia, Southern Illinois University press 1979 (ed., española en San Martín, Madrid 1983, 530 págs.).

${ }_{16}$ Vid. K. J. RuHL, Franco, Falange y III Reich. España durante la segunda guerra mundial, Akal, Madrid 1986, págs. 26-27. 
sobre el desenlace de la campaña de Rusia. Los militares habían calculado que se resolvería a lo sumo en dos meses, pero ahora era evidente que duraría mucho más y si se producía una acción aliada contra España o el norte de África no podía esperarse ayuda alemana.

\section{LOS ESTADOS UNIDOS ENTRAN EN LA GUERRA. INTRIGAS CONTRA FRANCO}

Así las cosas, el inesperado ataque japonés a Pearl Harbour en diciembre del 41 provoca la entrada de los Estados Unidos en la guerra. La extensión del conflicto al Pacífico incrementa inmediatamente los temores portugueses, que ven seriamente en peligro sus colonias de Timor y Macao. No es extraño, pues, que la iniciativa de una cumbre hispanolusa partiera de Portugal. La reunión Franco-Salazar tuvo lugar en Sevilla el 12 de febrero del 42 . Se habló naturalmente de la posible ayuda española en caso de ataque a las islas portuguesas, pero Franco expuso también su temor a que los aliados tomasen la Península como punto de partida para la apertura de un segundo frente. De Sevilla saldría una entente verbal, que por el momento se mantuvo en secreto, para asegurar la neutralidad ibérica y así se informó a Londres. Comenzaba, pues, a afianzarse en el pensamiento de Franco la conveniencia de girar hacia una neutralidad más estricta. No obstante, convenía mantener la ambigüedad, e inmediatamente después de la marcha de Salazar, Franco pronunció un discurso destinado a paliar los auténticos efectos de lo acordado con Portugal. Por el momento, esta nueva aproximación hispano-lusa, táctica habitual cada vez que se intuía un peligro cercano para la Península, se utilizó como una baza más, destinada a abonar el éxito propagandístico de cara a las negociaciones económicas que España estaba llevando a cabo con Alemania. No obstante, tampoco en esto obtuvo lo que buscaba. En un intento de compensar la amenaza para las importaciones de alimentos que había supuesto la intervención norteamericana en la guerra, España amenazó con cortar el suministro de wolframio a Alemania, pero era Portugal quien cubría el 60 por 100 de las importaciones alemanas de ese mineral. Fracasó, pues, este primer intento de hacer más llevadera la presión económica aliada presionando a su vez sobre Alemania.

La intervención norteamericana incidió también, aunque indirectamente, en la política interna, acelerando la crisis que culminaría con la 
caída de Serrano. En realidad, un sector del Ejército seguía pensando en la restauración monárquica y la evolución del conflicto afianzaba cada vez más la postura anti-intervencionista. El embajador británico, a través del fondo que recibía para propaganda, apoyaba las actividades monárquicas, sin excluir en sus conversaciones la posibilidad de un pronunciamiento encabezado por Kindelán. Incluso Serrano barajaba este tipo de alternativas. La documentación italiana, recientemente revisada, apunta como motivo central de su viaje a Roma, en junio del 42, procurar un contacto con don Juan y plantear la posibilidad de la restauración. Si la "revolución» falangista hubiera triunfado, tal hipótesis habría carecido de sentido, pero dadas las circunstancias no podía descartarse del todo. Claro está que se trataría de una restauración de acuerdo con Franco, al amparo de Falange y con el afiliamiento pro-Eje de don Juan. Pero el ex-rey no se avino a la maniobra, que tampoco interesaba a Mussolini para quien la Monarquía era "un enemigo natural de las revoluciones totalitarias" ${ }^{17}$.

Los alemanes también consideraron la posibilidad de intervenir en la política interna española, en la que contaban poder influir a través de la División Azul y de su comandante: Muñoz Grandes. Algunos generales monárquicos se habian puesto en contacto con él, pidiéndole que iniciara conversaciones con los dirigentes alemanes para hacer campaña a favor de don Juan. También la Falange auténtica, ala sindicalista compuesta por camisas viejas y por generales y voluntarios de la División Azul, que se había constituido en la primavera del 42 , veía en él un posible líder. Franco se da cuenta del peligro y a mediados de mayo le destituye. Pero los alemanes consiguen retenerle en su puesto algunas semanas más y el 12 de julio tiene lugar una entrevista entre Muñoz Grandes y Hitler. Ambos coincidieron en su visión de la política exterior, aunque el Führer le propuso esperar al éxito de la ofensiva alemana que podría servir como «fundamento de su gran misión» ${ }^{18}$.

A partir de ese momento se inicia un período oscuro en las relaciones hispano-alemanas, abriéndose, junto a la política oficial representada por el embajador Stohrer, siempre partidario de la no beligerancia española, una segunda vía: la diplomacia secreta, auspiciada por Ribbentrop, dispuesta a conseguir, aprovechando las disensiones internas, lo que no se había obtenido por la fuerza, es decir, una política pro-Eje sin reservas

17 Vid. Tusell y Garcia Qeuipo de Llano, ob. cit. págs. 162-64.

${ }^{18}$ Vid. K. J. RuHL, ob. cit., pág. 113. 
e incluso una intervención española quasi de motu propio en la guerra. Agentes alemanes se entrevistaron con destacadas figuras españolas e incluso llegó a presentarse a Hitler un plan detallado para un pronunciamiento militar, que tendría lugar en el otoño del 42 , y que incluia la invasión de España por tropas alemanas y la toma de Gibraltar. Dos acontecimientos relegaron tales hipótesis: el ataque soviético a Leningrado, que desbordó a los alemanes; y la crisis gubernamental de septiembre que supuso el desplazamiento de Serrano, sustituido en la cartera de Exteriores por Jornada.

\section{LA CAÍDA DE SERRANO. EL VIRAJE NEUTRALISTA}

La crisis del Gobierno, desencadenada en parte por el atentado de Begoña, que representó el vértice del enfrentamiento latente FalangeEjército ${ }^{19}$, significó el comienzo del viraje neutralista de la política exterior de Franco. Parece que la intervención norteamericana en la guerra y los temores sobre Canarias, a la vez que la obstinación de Hitler en el frente del Este, pesaron en esta evolución. En cualquier caso, su evidente oportunismo ha dado pie a especulaciones sobre la habilidad política de Franco. Serrano era considerado intervencionista acérrimo, partidario de la amistad con Alemania y especialmente con Italia, cuyo modelo político aspiraba a implantar en España a través de la Falange serranista. Precisamente esto último era lo que más se le reprochaba y lo que menos estaban dispuestos a consentirle: el monopolio del poder para "su» línea falangista, lo que equivalía al monopolio del poder para sí mismo. Durante los primeros momèntos del régimen, que coincidieron con los mayores y más espectaculares triunfos del Eje, la posición de Serrano, que llegó a acumular una considerable cantidad de poder al unir en sus manos la cartera de Exteriores y la de Gobernación con el consiguiente control de la prensa, parecía inexpugnable. Por eso, cuando comenzaron a trascender sus discrepancias con Franco y Jordana le sustituyó en el Ministerio de Exteriores, estallaron todos los resquemores acumulados contra él.

La caída de Serrano coincidió además con el cambio en la coyuntura bélica. Los alemanes parecían atrapados en el Este y la intervención

19 Vid. A. Marouina Barrio, «El atentado de Begoña», en Historia 16, 76, 1982, págs. 11-19. 
norteamericana había dado al conflicto un giro definitivo. Esto, por una parte, dio alas a los sectores del Ejército que siempre se habian mostrado anti-intervencionistas, alentando por otro a aquellos que aunque partidarios en un principio de dar facilidades al Eje habían recogido velas a la luz de la nueva situación. La evolución del conflicto y la suerte del régimen corrían paralelas. De ahí las especulaciones sobre la supuesta habilidad pólítica de Franco que supo navegar en tan tempestuosas aguas, saliendo victorioso en lo que al mantenimiento de su poder personal se refiere. De ahí también los reproches de Serrano ${ }^{20}$. Impulsó su ascenso mientras la victoria del Eje parecía inminente y el propio Franco estuvo dispuesto, así se lo ofreció a Hitler, a entrar en la guerra, utilizándole finalmente como chivo expiatorio cuando al evolución del conflicto y la tensión interna aconsejaban borrar pasadas veleidades.

No obstante, parece que el viraje neutralista, tal como los aliados interpretaron el nombramiento de Jordana ${ }^{21}$, tardó algo más en producirse. Franco todavía, un tanto irracionalmente, confiaba en la victoria del Eje y la medida respondía una vez más a su tradicional cautela, o a su desconfianza innata: cuando los aliados planeaban el asalto a la fortaleza de Europa, necesitaba un hombre prudente y sobre todo dúctil al frente de los asuntos exteriores. Sin embargo, Ribbentrop, en la línea de las anteriores intrigas contra Franco, pensó que el alejamiento de Serrano, cuya credibilidad había perdido muchos puntos, abría el cauce por el que podía incrementarse la presencia alemana en España, presionando desde fuera con la División Azul y desde dentro con la oposición a Falange. El nuevo hombre de los alemanes sería ahora Arrese, camisa vieja y vinculado a sectores antiserranistas, comenzándose las gestiones para su visita a Berlín.

\section{LA OPERACIÓN TORCH}

Pero un nuevo factor atajaría tales elucubraciones. El 24 de octubre del 42 comenzó la ofensiva aliada en el desierto. El 8 de noviembre se

20 Vid. R. Serrano SúNér, Memorias..., pág. 358-59.

${ }_{21}$ Vid. Sir S. HoARe (Viscount Templewood), Ambassador on Special Mission, Collins, London 1946, págs. 164-71 (ed. española en Sedmay, 1977). También C. J. H. HAYES, Wartime Mission in Spain (1942-1945), da Capo Press, New York reprint 1976 (edición española: Madrid 1946). 
produjo el desembarco en el norte de África. Era la operación Torch que Roosevelt y Churchill habían discutido desde junio del 42 y que abría el segundo frente prometido a los rusos ${ }^{22}$. Cabe preguntarse qué papel se atribuía en ella al Marruecos español. A mediados de agosto, Eisenhower había informado que tendría éxito si España permanecía neutral. No obstante, las posibilidades de una beligerancia española se estudiaron a fondo. En septiembre del 42 se había preparado el plan Backbone. Se partía de que los alemanes tratarían de llegar al Estrecho y lo harían presumiblemente a través de España. Si se producía la invasión, los aliados tendrían que ocupar el Marruecos español para prevenir que los alemanes pudieran cruzar a África por esa zona, pero no harían nada hasta que las tropas germanas hubieran atravesado los Pirineos.

Aunque Hitler seguía obsesionado con el frente del Este, Franco nunca había descartado una operación aliada en el norte de África y menos a partir de la entrada de los Estados Unidos en la guerra. De hecho, a comienzos de enero del 42 había ordenado el refuerzo de las guarniciones de Marruecos y puesto bajo su jurisdicción directa las colonias españolas. Al producirse el desembarco, aunque los embajadores británico y norteamericano presentaron sendas garantías de que los derechos españoles no serían violados, decretó la movilización parcial. La medida, exclusivamente dirigida contra Alemania que no había dado ninguna garantía similar, se justificó ante ella con la excusa de atajar una posible sublevación interna, alentada por los espectaculares avances aliados. Indirectamenre favoreció a los alemanes al crear una zona tope entre el Estrecho y los Pirineos. En diciembre del 42, Jordana visitó Lisboa. Ahora, no sólo se hizo pública la entente hispano-lusa, sino que se lanzó la idea de un «Bloque Ibérico de amistad mutua y paz eterna».

Así las cosas, tuvo lugar por fin la visita de Arrese a Berlín en enero del 43. Para entonces el desembarco aliado y la derrota ante Leningrado habían creado una situación estratégica nueva. Las tropas alemanas se hallaban atrapadas en el Este y Hitler se vio obligado a solicitar a Franco una garantía de que si se producía un ataque aliado en el Oeste, España se defenderia por sí misma, cubriendo así la retaguardia alemana. La nueva situación había permitido a España reabrir las negociaciones económicas estancadas desde septiembre. El convenio económico hispano-

${ }^{22}$ Cfr. Sir L. WoOWARD: British Foreing Policy in the Second World War, Vol. III, Londres 1972. Y la documentación publicada: Foreign Relations of United States, United States Government Printing Office, Washington 1956 y ss. 
germano se firmó el 16 de diciembre obteniendo España lo que buscaba: armas a cambio de materias primas. Una negativa alemana se habría interpretado entonces como el deseo de mantenerla débil ante una posible invasión, con lo que a su vez Hitler no habría obtenido la ansiada garantía que repetidamente solicitaba de Franco. En este contexto, las anteriores intrigas alemanas carecían ya de sentido. Arrese, por otra parte, se reveló impenetrable durante su estancia en Berlín, archivándose definitivamente los planes para unir a España más estrechamente al Eje y en caso necesario provocar su entrada en la guerra, a costa incluso de la caída de Franco. El nuevo embajador alemán: Moltke - Stohrer había sido fulminantemente cesado tras la firma del convenio económico- sería el encargado de obtener la garantía que Franco se avino finalmente a dar, firmándose el 12 de febrero de 1943 el protocolo secreto hispanoalemán que incluia el suministro de armas a España, por parte de Alemania, y confirmaba que Hitler había descartado su entrada en la guerra.

\section{MUSSOLINI PIDE AYUDA A FRANCO}

A esta alturas, Franco debía ser consciente de que la superviviencia de su régimen dependía de la benevolencia de los aliados. Convenía, pues, alejarse de las ambigüedades de la no beligerancia e ir afianzando el camino de la neutralidad. El primer paso dado en este sentido, la idea del Bloque Ibérico, se reforzo con el inicio de una campaña de paz en la que España se ofrecía como mediadora, volviendo a la vieja idea de constituir una especie de federación de naciones católicas en torno a la figura del papa y enviando notas a países neutrales como Irlanda, Suecia y Suiza. Portugal se mostró dispuesto a colaborar, pero el proyecto, tal como lo presentaba la diplomacia española, no llegó a cuajar ${ }^{23}$.

Fue entonces, en un momento en que todo parecía alejar a España de la guerra, cuando Mussolini, en un intento desesperado por apuntalar su régimen y tratando de compensar a los italianos con una victoria en el Mediterráneo, insistió, más ardientemente que nunca, en la necesidad de ligar a España al Eje. Parece que a esta decisión no fue ajena una

${ }^{23}$ Vid. A. Marquina BarRio, La diplomacia vaticana y la España de Franco, 1936-1945, CSIC., Madrid 1982, págs. 315-330; y Actes et Documents du Saint Siege rélatifs a la seconde guerre mondiale, Librería Editrice Vaticana 1965-1973. 
carta de Franco, hasta ahora desconocida, escrita el 30 de enero del 43 , en la que expresaba sinceramente su alineación con la Italia fascista y su inquietud ante la nueva situación bélica, apoyada en el protagonismo norteamericano y en la capacidad de resistencia rusa ${ }^{24}$. La coincidencia de intereses y de juicios pudo dar alas en un momento tan crítico al Duce, y tampoco contradice, por otra parte, el viraje neutralista de la política de Franco, aunque introduce matizaciones de importancia al subrayar cuán a su pesar lo hizo.

Pero Hitler, que seguía obsesionado con Rusia, no sólo no cedió sino que retiró el grueso de sus tropas de los Pirineos, enviándolas al frente ruso. En realidad, los alemanes habían caído en la trampa, cuidadosamente preparada por el Servicio Secreto británico, destinada a hacerles creer que el desembarco aliado no se produciría en Sicilia, como efectivamente ocurrió. La operación asestó el golpe de gracia al régimen de Mussolini que fue sustituido por Badoglio al frente del Gobierno. La noticia no se dio en España hasta el 27 y sin excesivo alarde, incluso con buscada ambigüedad, pero esto no impidió que Franco se lavase literalmente las manos ante la suerte de su antiguo aliado, al que ya, cortés pero firmemente, con ocasión de la entrega de credenciales del nuevo embajador italiano en España el 20 de abril, había hecho saber que contaría con la intervención española en la guerra, por mucho que «de corazón» desease la victoria del Eje. Era evidente, por otra parte, que a partir de este momento Estados Unidos y Gran Bretaña por un lado y la URSS por otro tomaban las riendas de la guerra. El hecho de que durase dos años más no fue ajeno al de que los países peninsulares no cortaran el suministro de wolframio, sin el cual la industria bélica germana apenas se hubiera sostenido más de unos meses.

\section{DE LA NO BELIGERANCIA A LA NEUTRALIDAD}

No es difícil deducir que estos acontecimientos repercutieron en España en un camino cada vez más claro hacia la neutralidad. Aunque todavía durante la primavera de! 43 las declaraciones públicas y las informaciones de prensa mantuvieron una posición ambigua, la suerte estaba echada. Los aliados, que no habían descuidado las relaciones con

${ }^{24}$ Vid. J. TuseLL, art. cit. supra, págs. 20-24. 
los países peninsulares, llegaron a un acuerdo con Portugal para la utilización de las Azores y decidieron actuar con mayor dureza frente a España. En julio del 43 el embajador británico exigió la retirada de la División Azul, y el norteamericano el abandono de la no beligerancia. El 1 de octubre del 43, Franco dio el primer paso hacia la neutralidad definiendo la posición de España como «neutralidad vigilante». El reconocimiento público estaba hecho, aunque como ha subrayado Marquina ${ }^{25}$, el decreto de no beligerancia no se había derogado oficialmente. En Alemania, que ya sólo veía en España un abastecedor de materias primas, el hecho, así como la solicitud de retirada de la División Azul, se aceptó sin problemas.

Por su parte, los aliados, que ya no estaban dispuestos a consentir la habitual táctica dilatoria de Franco, decidieron sustituir las protestas verbales por una presión económica bien orientada. Los norteamericanos exigieron que se suprimiera la exportación de wolframio a Alemania, amenazando con bloquear el transporte de petróleo y cortar los suministros de trigo y caucho ${ }^{26}$. En estas condiciones, Franco debió convencerse de que era necesario pactar. El 2 de mayo del 44 se firmó el acuerdo con los aliados, accediendo España a todas sus peticiones: retirada de la Legión española, resto de la División Azul, del frente del Este; cancelación de toda exportación de wolframio a Alemania; entrega de los buques italianos internados en puertos españoles; expulsión de los agentes del Eje y supresión del consulado alemán en Tánger. A cambio, se levantó el embargo del petróleo y se hicieron promesas de consideración en el terreno económico. A partir de este momento, las relaciones con sus antiguos amigos fueron prácticamente inexistentes. Las tropas aliadas entraron en Roma en julio del $44 \mathrm{y}$, aunque Mussolini no fue ejecutado hasta abril del 45, Franco hacía tiempo que le había abandonado a su suerte. En cuanto a las relaciones con Alemania, desde el 2 de septiembre del 44 , cuando los aliados cruzaron la frontera germana, hasta el 8 de mayo del 45, día de la capitulación, se habían limitado a cuestiones de trámite. El último embajador alemán, Dieckoff, había sido llamado a Berlín el 2 de noviembre del 44 y ya no regresó.

Franco se aferraba ahora a una última baza: el anticomunismo. Estaba convencido de que la construcción de la paz no podía apoyarse en

${ }^{25}$ A. Marouina Barrio, España en la política de seguridad occidental..., pág. 108.

${ }^{26}$ Vid. J. W. CORTADA, United States-Spanish relations. Wolfram and World War II, (edición española en Dopesa, Barcelona 1963). 
el acuerdo anglo-ruso y así se lo comunicó a Churchill, pero éste que se negaba a aparecer como aliado del fascismo, anunció a Franco que no le secundaba en su organización de la paz. En estas circunstancias se convenció de que el futuro de su régimen estaba en el acuerdo unilateral con los Estados Unidos. A comienzos del 45 concluyeron las negociaciones de los acuerdos ATC, que abrieron el camino a la penetración norteamericana en España y proporcionaron al régimen una base a la que agarrarse en el difícil contexto de la segunda postguerra mundial.

A modo de recapitulación final, podemos concluir que hubo al menos tres ocasiones en las que la suerte de España estuvo a punto de unirse a la de las potencias del Eje. No cabe duda de que en los primeros momentos de la guerra, cuando parecía inevitable una rápida y fulgurante victoria alemana, Franco no sólo no tuvo inconveniente en entrar sino que se ofreció personalmente a hacerlo. La capacidad de resistencia británica y las reservas alemanas ante las reivindicaciones españolas lo impidieron. La segunda se produjo tras el desembarco aliado en el norte de África, es decir, cuando la guerra se trasladó nuevamente al teatro mediterráneo. Ahora fue España, desconfiando ya de una victoria rápida, la que eludió un compromiso efectivo. La tercera, finalmente, cuando Mussolini, tras el desembarco aliado en Sicilia, lo solicitó, pero para entonces ya se había iniciado la operación de maquillaje del régimen y Franco no dudó en abandonar a quien tan generosamente le había ayudado en la guerra civil. La presión económica aliada y la amenaza de invasión, que planeó sobre España a lo largo del conflicto, proporcionaría la excusa definitiva para mantenerse al margen de una guerra cuya propia evolución fue descartando paulatinamente la intervención de un peón secundario, como España, permitiendo a la vez a Franco, que supo aprovecharlo, mantenerse en el poder. 